\title{
Research on Industry Agglomeration of Construction Machinery Industry Based on Location Quotient Index
}

\author{
Xue YANG $^{1, a}$ \\ ${ }^{1}$ School of Management Science, Xuzhou Institute of Technology, Xuzhou, Jiangsu, China \\ ayangxue9622@xzit.edu.cn
}

Keywords: Industrial agglomeration, location quotient, construction machinery industry.

\begin{abstract}
The agglomeration degree of construction machinery industry is calculated based on the data of the gross value of industrial output of the machinery industrial from 2007 to 2010 using the location quotient index. The results show that the cluster of construction machinery industry has been basically formed, and mainly concentrated in the eastern coastal areas and Hunan, Sichuan, Guangxi, etc.
\end{abstract}

\section{Introduction}

Industrial agglomeration was studied at the end of the 19 century. Industrial cluster is a geographical phenomenon in the process of industrial development. It means that a number of industrial enterprises are centralized in a certain region in order to obtain agglomeration benefits. Research and practice both at home and abroad show that industrial agglomeration can bring agglomeration effect, symbiotic effect, synergy effect, regional effect, structure effect, knowledge spillover effect and many other advantages, which plays a crucial role to accelerate the industrial innovation, improve the coordination and symbiosis, optimize the allocation of resources, improve the industrial competitiveness, create the industrial ecological environment and so on.

The degree of industrial agglomeration is the measurement indexes to measure the industrial agglomeration degree of most companies in the upstream and downstream industry chains in a certain area. The degree of industrial agglomeration presents one aspect of the industrial competitiveness and the economic strength of a region or nation. It is an important part of the study of industrial agglomeration to study on the measure method of industrial agglomeration degree and the measure the degree of industrial agglomeration effectively. It has a great significance in promoting the development of regional economy, developing the industrial cluster theory and the empirical study.

After 50 years of development, the construction machinery industry of china has begun to take shape. By the end of 2010, there have been more than 1500 enterprises above designated size, 337100 employees, 350 billion-yuan total assets in the nation-wide construction machinery industry. China became a big manufacturing country of construction machinery in the world as sales revenue ranked first in the world in 2009 and construction machinery production and sales surpassed the U.S., Japan and other countries in 2007 , which not only makes a positive contribution to the development of world construction machinery, but also promotes to the GDP of our country with increasing trend year by year (see Table 1), and it appeared gradually that the status and role of strategic pillar industry of the construction machinery industry. Therefore, this paper makes an empirical study on the agglomeration degree of the construction machinery industry through neatening the various measure methods of the industrial agglomeration in order to confirm and recognize the construction machinery industrial cluster in china. 
Table 1: the total output value of construction machinery industry accounted for the proportion of GDP in 2006-2010 years

Unit: [million yuan]

\begin{tabular}{cccc}
\hline GDP & \multicolumn{2}{c}{$\begin{array}{l}\text { The total output value of } \\
\text { construction machinery } \\
\text { industry }\end{array}$} & $\begin{array}{l}\text { The total output value } \\
\text { accounted for } \\
\text { proportion of GDP }\end{array}$ \\
\hline 2006 & 216314.4 & 1050.6 & $0.49 \%$ \\
2007 & 265810.3 & 1384.9 & $0.52 \%$ \\
2008 & 314045.4 & 1689.8 & $0.54 \%$ \\
2009 & 340902.8 & 1955.5 & $0.57 \%$ \\
2010 & 401202.0 & 3066.6 & $0.76 \%$ \\
\hline
\end{tabular}

Data sources: China statistical yearbook, Chinese construction machinery industry yearbook

\section{Choice of Measure Methods of Industrial Agglomeration Degree}

In the domestic and foreign research literature, early research on the measure methods of industry agglomeration mainly focus on the qualitative research, including the expert advice, enterprise survey, which mainly analyses the industrial agglomeration degree through participant observation, in-depth interviews. This qualitative analysis method has the advantage of simple operation, but could not meet the analysis need due to the lack of system data in study. With the development and perfection of the theory of industrial agglomeration, the measure methods of industrial agglomeration degree have been updated. There are the following methods: Concentration Ratio, Location Quotient, Herfindahl Index, Space Gini Coefficient, EG Index etc.. These measure methods are the most common research methods, and each has its advantages and disadvantages. Among them, it is relatively easy to obtain the related data of location quotient index, simple to calculate, and can reflect the main characteristics of regional industry. Therefore, this paper will mainly use location quotient index to measure the agglomeration degree of the construction machinery industry considering the availability of data.

Location Quotient (LQ) is used to measure the spatial distribution of a regional factors, reflect the degree of specialization and centralization in a particular industry, and it is usually calculated by the total output or employment. The calculation formula is shown in the formula (1):

$$
L Q_{\mathrm{i}}=\frac{\mathrm{e}_{\mathrm{i}} / \mathrm{e}}{E_{\mathrm{i}} / E}
$$

Among them, $e_{i}$ is the total output value (employment)of $i$ industry in a region; $e$ is the total output value (employment)of all industries in the region; $E_{i}$ is the total output value (employment)of $\mathrm{i}$ industries in a nation; $\mathrm{E}$ is the total output value (employment)of all industries in a nation. The smaller the value of $\mathrm{LQ}_{\mathrm{i}}$ is, the smaller the proportion of the percentage of the total output value of the industry (employment) and the total output value (employment) in the region and the percentage of the total output value (employment) of the industry and the total output value (employment) in a nation is, the lower the agglomeration degree of the industry in the region becomes. When $\mathrm{LQ}_{\mathrm{i}}>1$, it shows that agglomeration advantage of the industry in the region is strong; when $L Q_{i}=1$, it shows that the agglomeration advantage of the industry in the region is not obvious; when $L_{2}<1$, it shows that that the agglomeration advantage of the industry in the region is weak. The higher the location quotient index is, the stronger the industrial agglomeration advantages in the region becomes, the more obvious the agglomeration phenomenon appears.

The location quotient index is widely used in the study of measurement of the industrial 
agglomeration by experts and scholars. Zhou Suping (2012) calculated and sequenced the agglomeration degree of the large and medium-sized high-tech enterprises cluster in 30 regions of China using the location quotient index, and screened out 12 regions with higher agglomeration degree. Xu Yongbing and Jia Qiang (2008) studied the development of industrial clusters of Hebei province using the location quotient. Liang Huafeng (2010) carried out a research on agglomeration level and trend of Macao service industry from the angle of regional economy by calculating the location quotient index of the Macao service industry.

\section{Measure to Agglomeration Degree of Construction Machinery Industry}

According to the calculation method of the location quotient index, this paper selects the total output value of the construction machinery industry 2007-2010 years of all regions of the country to calculate the location quotient index. The original data mainly comes from the China Statistical Yearbook, China Construction Machinery Industry Yearbook, Provincial Statistical Yearbook, China Economic Information Network and Construction Machinery Industry Risk Analysis Report Published annually by Beijing World the Future Investment Consulting Co., Ltd. The location quotient index of the construction machinery industry of all regions 2007-2010 years is calculated on the basis of location quotient index formula (see Table 2).

Table 2: the calculation results of location quotient of the construction machinery industry of

China 2007-2010 years (calculated using the total output value of industry)

\begin{tabular}{|c|c|c|c|c|c|c|c|c|c|}
\hline \multirow{2}{*}{ region } & \multicolumn{4}{|c|}{ location quotient } & \multirow{2}{*}{ region } & \multicolumn{4}{|c|}{ location quotient } \\
\hline & 2007 & 2008 & 2009 & 2010 & & 2007 & 2008 & 2009 & 2010 \\
\hline Jiangsu & 1.42 & 1.52 & 1.49 & 1.41 & Tianjin & 0.42 & 0.37 & 0.43 & 0.88 \\
\hline Shandong & 1.77 & 2.01 & 1.68 & 1.76 & Shaanxi & 0.47 & 0.67 & 0.49 & 0.58 \\
\hline Hunan & 8.95 & 9.49 & 7.19 & 8.99 & Hubei & 0.18 & 0.10 & 0.38 & 0.25 \\
\hline Sichuan & 2.02 & 2.03 & 1.58 & 2.02 & Beijing & 0.22 & 0.29 & 0.29 & 0.37 \\
\hline Fujian & 1.82 & 1.75 & 1.35 & 1.51 & Neimenggu & 0.21 & 0.30 & 0.14 & 0.09 \\
\hline Guangxi & 2.44 & 2.64 & 2.29 & 2.40 & Jiangxi & 0.36 & 0.27 & 0.39 & 0.17 \\
\hline Anhui & 1.99 & 1.76 & 1.22 & 1.51 & Jilin & 0.07 & 0.04 & 0.12 & 0.16 \\
\hline Shanghai & 0.62 & 0.95 & 0.78 & 1.08 & Guizhou & 0.46 & 0.33 & 0.40 & 0.25 \\
\hline Henan & 0.84 & 0.65 & 1.29 & 1.26 & Chongqing & 0.04 & 0.13 & 0.12 & 0.15 \\
\hline Liaoning & 0.20 & 0.20 & 0.38 & 0.42 & Yunnan & 0.01 & 0.00 & 0.08 & 0.10 \\
\hline Guangdong & 0.10 & 0.14 & 0.12 & 0.11 & Heilongjiang & 0.10 & 0.10 & 0.04 & 0.09 \\
\hline Zhejiang & 0.19 & 0.24 & 0.40 & 0.25 & Xinjiang & 0.00 & 0.00 & 0.03 & 0.04 \\
\hline Hebei & 0.25 & 0.16 & 0.43 & 0.29 & Shanxi & 0.04 & 0.00 & 0.01 & 0.02 \\
\hline
\end{tabular}

The location quotient index is greater than 1 in Hunan Province, it means that the agglomeration degree of the construction machinery industry in this region is much higher than the national average level, and the relatively mature construction machinery industry cluster has formed. According to the statistical data by the Future Ltd, the proportion of assets, income, profit of construction machinery industry in Hunan and China has been ranked the first in the country (see Figure 1). The proportion of assets is $30.65 \%$, profit $32.82 \%$ in 2010 , closing to $1 / 3$ of the country, which is double that of Shandong province which ranked the second in the country. Some enterprises in Hunan province have become the representative enterprises in the construction machinery industry, such as Sany, Zoomlion, Sunward and other outstanding enterprises. The status of construction machinery industry cluster in Hunan Province is more obvious which agrees with the calculated results of the location quotient. 


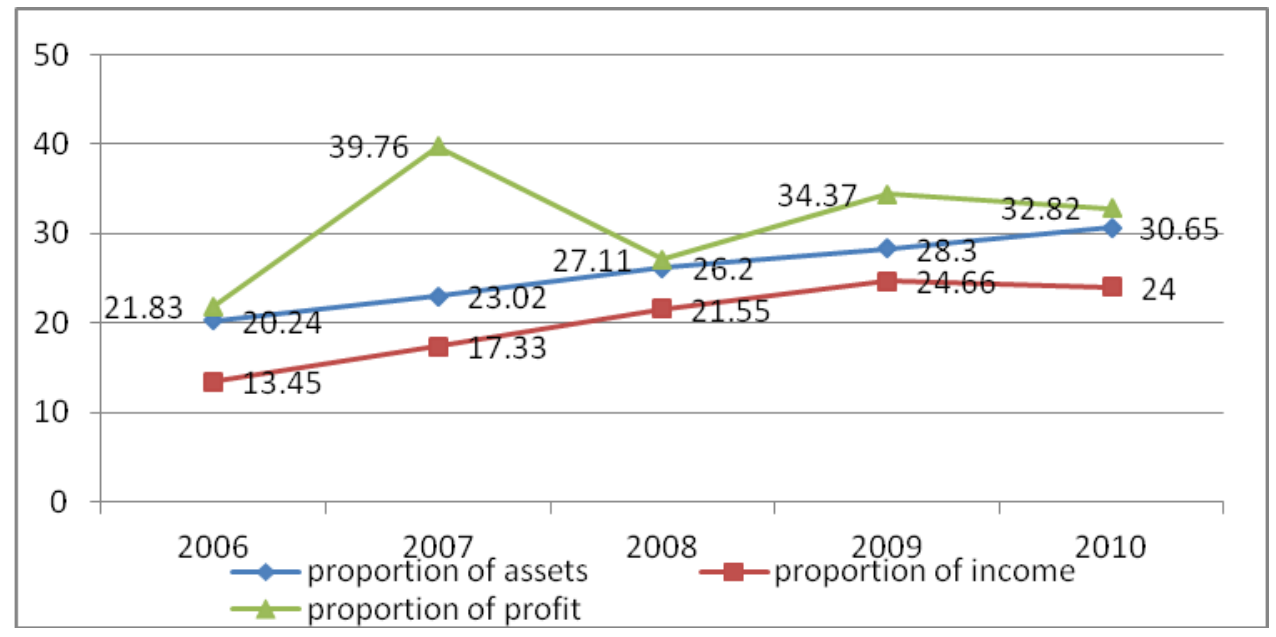

Fig. 1: the status of 2006-2010 Hunan construction machinery industry

These regions that the location quotient index is more than 1 are Jiangsu, Shandong, Sichuan, Fujian, Guangxi in 2007-2010.This indicates these regions have also formed the industrial agglomeration cluster. According to 2010 data, the total assets, sales incomes and total profit of Shandong Province and Jiangsu Province were ranked the second and the third respectively, followed by Sichuan, Guangxi and Fujian. The total assets of the top six regions accounted $73.02 \%$ of the whole industry, the sales incomes accounted $74.84 \%$, the total profit accounted $78.58 \%$. In these regions some well-known enterprises in the industry, such as Xugong, Shantui, Lingong, Liugong, Xiagong and the upstream and downstream enterprises in related construction industry chain, have gradually gathered and occupied $49.37 \%$ of the national enterprises, formed six construction machinery industry bases in China (see Table 3).

Table 3: six construction machinery industry bases in China

\begin{tabular}{|c|c|c|}
\hline place & $\begin{array}{l}\text { representative } \\
\text { enterprises }\end{array}$ & main machinery products \\
\hline $\begin{array}{l}\text { Jiangsu } \\
\text { xuzhou }\end{array}$ & Xugong Group & construction cranes, bulldozers, loaders, excavators \\
\hline $\begin{array}{l}\text { Jiangsu } \\
\text { changzhou }\end{array}$ & Changlin Group & $\begin{array}{l}\text { machine roller, earthmoving machinery, road } \\
\text { machinery, wheel loader }\end{array}$ \\
\hline $\begin{array}{c}\text { Hunna } \\
\text { changsha }\end{array}$ & $\begin{array}{l}\text { Sany, Zoomlion, } \\
\text { Sunward }\end{array}$ & $\begin{array}{l}\text { concrete machinery, lifting machinery, road } \\
\text { machinery }\end{array}$ \\
\hline $\begin{array}{l}\text { Fujian } \\
\text { Xiamen }\end{array}$ & Xiagong Group & loaders, forklifts, road machinery \\
\hline $\begin{array}{l}\text { Guangxi } \\
\text { Liuzhou }\end{array}$ & liugong Group & loader, excavator, small excavator \\
\hline $\begin{array}{l}\text { Shandong } \\
\text { Jining }\end{array}$ & Shantui Group & bulldozer, excavator \\
\hline
\end{tabular}

Data source: Beijing World the Future Investment Consulting Co., Ltd 2010 construction machinery industry risk analysis report 
The location quotient index of Shanghai and Anhui is greater than 1 in 2009-2010, which shows that the agglomeration trend of construction machinery industry has gradually formed with the development in recent years. some enterprises, such as Sany, Yuchai, Liugong, etc., are attracted successively to the Yangtze River Delta to build factories or merge enterprises because of its unique geographical advantages, excellent human resources and logistic conditions, which makes the Yangtze Delta the important base of China construction machinery industry cluster and products distribution center, also stimulates the development of construction machinery industry of Hangzhou, Shanghai, Ma'anshan, Hefei and other surrounding regions. Therefore, the agglomeration trend has become increasingly obvious in these regions in recent years, which is also proved from the calculation results of location quotient index.

The location quotient index of other provinces is less than 1. This shows the agglomeration of construction machinery industry is still not formed in these areas.

\section{Conclusion}

Using the analysis of the location quotient index of China construction machinery industry 2007-2010 years, the results show that the construction machinery industry cluster has been basically formed, mainly concentrated in the eastern coastal areas and Hunan, Sichuan, Guangxi etc., in which many well-known enterprises and main cooperation enterprises gathered. The basic formation of four major construction machinery industrial cluster includes Hunan construction machinery industrial cluster with Zoomlion, Sany, Sunward as the leader, Xuzhou construction machinery industrial cluster with Xugong Group as the core, Shandong construction machinery industrial cluster with Lingong, Fangyuan, Komatsu, Daewoo, Jining, Linyi as the center, Yangtze Delta construction machinery industry cluster with Changlin, Longgong, Shanghai Huajian and other famous enterprises as the representative. In addition, there are more vigorous construction machinery industry clusters in Sichuan, Guangxi, Fujian.

From the actual research results, some advantages coexist with some disadvantages using the location quotient index to measure the industrial agglomeration degree. Its advantages are that the location quotient index is simple and convenient to calculate, and can reflect figuratively the industrial agglomeration level of the region. Its disadvantages are that the location quotient index can not reflect the differences of the specific situation of industrial organization and the economic development level, and its results may be inconsistent with the actual situation because the location quotient index of the region which the agglomeration degree is highest is not necessarily biggest. Take Jiangsu for example, the agglomeration degree of the construction machinery industry of Jiangsu province is relatively higher, only after Hunan and Shandong, but the location quotient index is not relatively higher.

\section{Acknowledgement}

This research was financially supported by the social science research projects of XZIT (Research on Evaluation of Regional Innovation Ability of Industrial Clusters: Taking the Cluster of Xuzhou Construction Machinery Group for an Example )

\section{References}

[1] Zhang Changli. Summary of the Theory of Industrial Agglomeration [J]. Modern Management Science, 2004, 12:32-34.

[2] Peng Geng. Study on the Measurement of Industrial Agglomeration Degree [J]. Technology and Innovation Management, 2010, 2:181-184.

[3] One of a series of Chinese Industry Annual Report in 2011: Construction machinery [EB/OL], 
China economic information network.

[4] Zhou Suping. Establishment and Application of Location Quotient Model for China's Large and Medium-sized High-tech Enterprises Cluster [J]. Science \& Technology Progress and Policy, 2012, 04:75-79.

[5] Xu Yongbing, Jia Qiang. Study on the Development of Industrial Clusters in Hebei Province with the Location Quotient as an Angle of View by Six Pillar Industries [J]. Economy and Management, 2008, 09:86-89.

[6] Liang Huafeng. Analysis of Macao Service Industry Agglomeration -- An Empirical Study of Location Quotient [J]. Modern Management Science, 2010, 02:33-35.

[7] 2011 Construction Machinery Industry Risk analysis Report [R], Beijing World the Future Investment Consulting Co., Ltd. 